This item was submitted to Loughborough's Research Repository by the author.

Items in Figshare are protected by copyright, with all rights reserved, unless otherwise indicated.

\title{
Can electronic textbooks help children to learn?
}

PLEASE CITE THE PUBLISHED VERSION

PUBLISHER

(C) Emerald Group Publishing Limited

VERSION

AM (Accepted Manuscript)

LICENCE

CC BY-NC-ND 4.0

REPOSITORY RECORD

Maynard, Sally, and Emily Cheyne. 2019. "Can Electronic Textbooks Help Children to Learn?”. figshare. https://hdl.handle.net/2134/3624. 
This item was submitted to Loughborough's Institutional Repository (https://dspace.lboro.ac.uk/) by the author and is made available under the following Creative Commons Licence conditions.

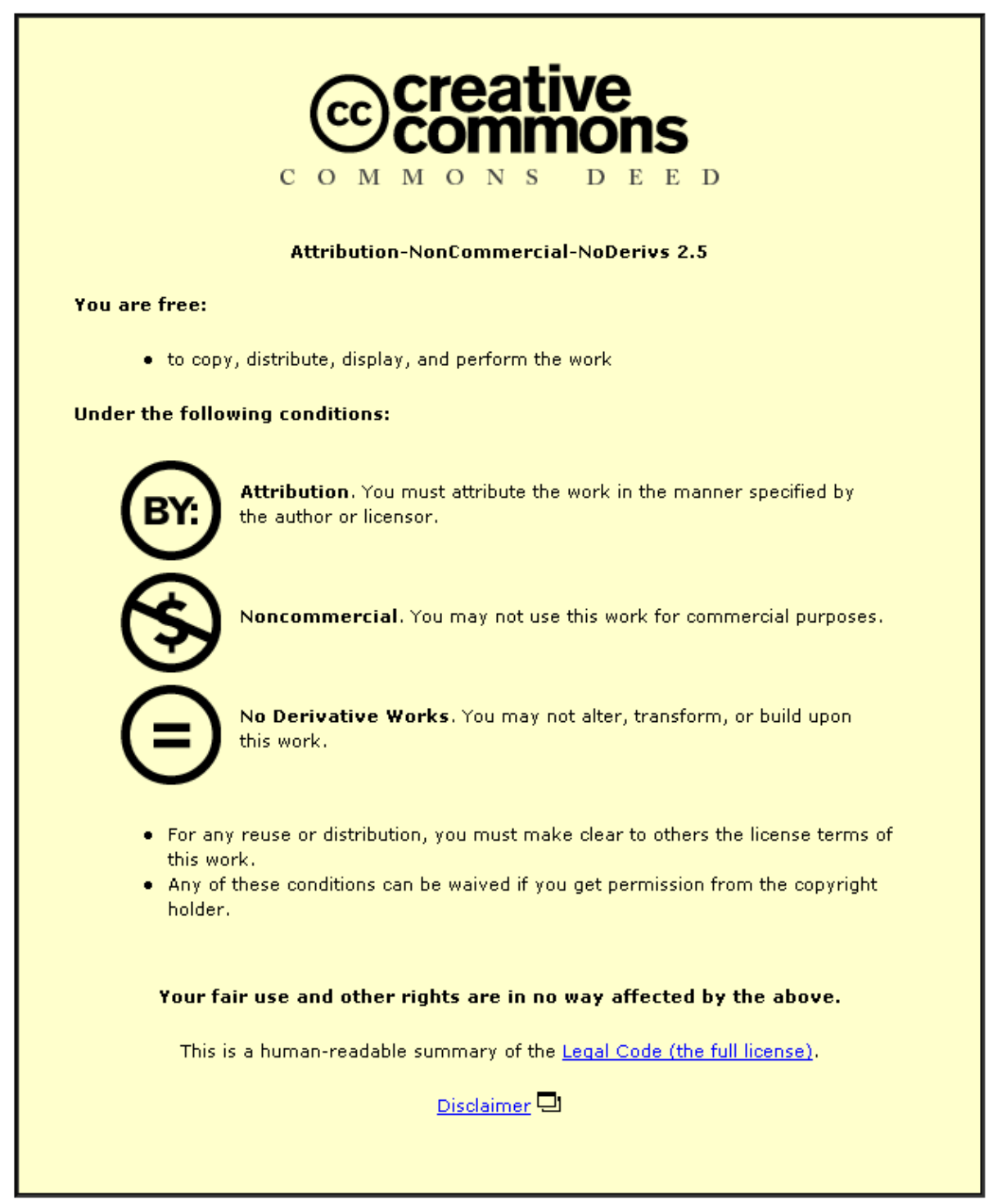

For the full text of this licence, please go to: http://creativecommons.org/licenses/by-nc-nd/2.5/ 


\section{Authors:}

Dr Sally Maynard

Library and Information Statistics Unit (LISU)

Loughborough University

Epinal Way

Loughborough

Leicestershire

LE11 3TU

e-mail: s.e.maynard@lboro.ac.uk

Telephone: +44 (0) 1509222179

Fax: +44 (0) 1509223072

Ms Emily Cheyne

Laing O’Rourke Plc

Bridge Place, Anchor Boulevard

Admirals Park, Crossways

Dartford

Kent

DA2 6SN

e-mail: echeyne@laingorourke.com

Telephone: +44 (0) 1322296703

Fax: +44 (0) 1322296262

\section{Biography:}

Sally Maynard is the Research Associate for the Library and Information Statistics Unit (LISU) based at Loughborough University. Emily Cheyne is a Graphic Designer with Laing O’Rourke, a construction company based in Kent. 


\section{Can Electronic Textbooks Help Children to Learn?}

\section{ABSTRACT}

Purpose - This paper investigates the potential electronic textbooks (e-textbooks) have to augment the learning and education of children.

Design/methodology/approach - The study consisted of a total of 60 pupils, split into five groups of 12 participants (six boys and six girls). Each of the five groups were in turn split into two sub-groups of six (three boys, three girls): one sub-group used the printed textbook, while the other used a CD-ROM on a laptop computer. The pupils completed a group test and an individual multiple choice test on information found in the textbooks.

Findings - The study showed that the e-textbook was widely accepted by the participants, and motivated group participation. Those using the e-textbook achieved significantly higher test results on average in the group test. Higher (but not significant) average results were achieved by e-textbook users in the individual test. Research limitations/implications - $\quad$ An acknowledged limitation of the study is that the textbooks used for the study were not identical in content. They were equivalent according to subject and recommended age range, but did not contain specifically the same information. Further studies would benefit from making use of an electronic version which is identical, or more similar, to a printed textbook. It would also be worthwhile to investigate the effects of long-term use once the novelty value of the electronic book has subsided.

Originality/value - The paper aims to fill the gap in the original literature on the subject of how children relate to and learn from electronic textbooks. The research is of particular interest to teachers, librarians and parents.

Keywords Electronic books; Children (age groups); Learning

Paper type Research paper

\section{Introduction}

The latest publishing phenomenon could be said to be electronic books (also known as e-books) (Cox and Ormes, 2001). The term "electronic book" dates back to the late 1960s (Henke, 2001), and a recent definition by Feather and Sturges (1997) is, "a text analogous to a book, that is in digital form to be displayed on a computer screen" ( $p$ 130). The electronic book is a significant new medium which can offer added value to the printed book through its potential for including other media in addition to text on its pages. It is a document designed to be viewed on a computer screen, integrating 
the classical book structure with features that can be provided within an electronic environment (Landoni et al, 2000).

Electronic books may be accessible on a variety of media, for example, on CD-ROM, the Internet and dedicated, portable reading devices. They may also include a variety of types of content (e.g. fiction, non fiction), and may vary as to presentation (e.g. book metaphor) and functionalities (e.g. audio, animation). A textbook is "a book used as a standard source of information on a particular subject" (Collins Concise Dictionary, 1999). An electronic textbook (or e-textbook) has similar content, and could be seen as a subset of the more generic concept of an electronic book. More specifically, an e-textbook is an e-book which contains educational material for teaching and learning methods (Landoni and Diaz, 2003). E-textbooks are therefore educational materials that have been electronically published to assist both teaching and learning methods. They present learning material within a computer environment, via media such as CD-ROM or the Internet (Collins et al, 1997).

There has been a rapid expansion of educational multimedia since the early 1990s (Boyle, 2002), and converting printed publications such as the textbook into an electronic interactive form is likely to prove beneficial (Shiratuddin and Landoni, 2000). It has been argued that the electronic book is particularly suited to enhancing learning outside of the classroom (Desrosiers, 1996), and recent technological developments have produced a powerful incentive to provide such electronic material for educational purposes (Landoni and Diaz, 2003). Printed textbooks are also often out-of-date in comparison to e-textbooks, with the printed version usually being updated and replaced on average every eight years (Dugan, 2003).

Current teaching activities are trying to combine the best network-based, teacherbased and courseware-based resources (Shiratuddin and Landoni, 2001). Electronic learning provides faster and greater access to information for education (Hamilton et al, 2001). Hambrecht (2000) suggests that electronic education is effective because it "offers collaboration and interaction with experts and peers as well as a higher success rate than alternatives”. However, consideration should be given to the implications of taking on this e-learning initiative, including financial support, staff workload and changing roles (Wilson, 2003).

In a similar way to their printed equivalents, e-textbooks allow students to underline important sentences, write notes and look up unfamiliar words (Cox and Ormes, 2001). They add functionality in that they permit readers to change font sizes, watch 
video clips and interact with the various other dynamic benefits offered by the e-book. It has also been shown that children can benefit from the added features of electronic books (Maynard and McKnight, 2001). E-textbooks also have an advantage over the printed textbook in that they reduce the number of printed textbooks that have to be carried to, from and around school by pupils. This is because of their portability: a number of electronic titles can be carried at once (in computer memory or on a network). They are also space saving, which can be particularly helpful in libraries (Cox and Ormes, 2001).

In the past, e-books have been expensive, priced either at the same level or higher than printed books. Recently, however, costs have begun to be reduced (Mayfield, 2000), and a fall in prices could prove a major step towards the use of e-textbooks in schools. Christie (1998) believes that it will be more cost-effective in the long run to provide all students with curriculum materials on CD-ROM, or through the Internet, than to continue buying printed textbooks.

E-textbooks also benefit from instant accessibility via downloading from the Internet. For example, XanEdu's electronic course packs can be available within 24 hours or less, compared to the usual procedure which takes four to six weeks to get print articles copyright cleared, produced and delivered (Mayfield, 2000).

CD-ROMs are currently in use in various British schools as a means of electronic teaching (Collins et al, 1997). Furthermore, hypertextbooks are already a popular means of interactive learning on the Internet in America (O’Keefe, 1995).

Hypertextbooks are digital documents which consist of learning modules that allow students to learn at their own pace, link to help resources and hand in assignments via e-mail.

Introducing e-textbooks into schools could represent a demographic and generational shift. If children use e-books in school at a young age, they will be more likely naturally to adapt to electronic developments, and be less attached to the printed book. It is this generation who are the future consumers, and as a result the e-book may be accepted by them and so eventually become successful (Turnbull, 2000a).

Despite the many advantages associated with e-textbooks, there are also some clear disadvantages. The first to note is the problems concerned with reading from screens, which may lead users to read more slowly or opt to print the document and view it in printed form (Wilson, 2001). However, it should be noted that developments in 
technology are currently improving screen quality. It has also been argued that etextbooks exhibit the potential for complexity, leading to various difficulties associated with usability (Landoni and Gibb, 2000; Catenazzi and Sommaruga, 1994) and some e-textbooks may promise complex added functionality, but actually deliver limited multimedia features (Shiratuddin et al, 2003). It is also necessary to ensure that there is sufficient memory space on computer hard disks both to store the electronic text and run the software (Walton, 2002), which could cause problems in schools where computer equipment is not particularly up-to-date.

There has recently been a certain amount of research into children's comprehension of electronic books, mainly concerned with those which concentrate on fiction. For example, Greenlee-Moore and Smith (1996) investigated the effects on the reading comprehension of nine and ten year old children of printed narrative texts of different length and complexity, compared to the same narrative texts presented on interactive CD-ROM software on the computer. A study by Trushell et al (2001) took as its basis research indicating that reading an electronic book can have beneficial outcomes for pupil's reading. The study investigated small groups of nine and ten year children reading an electronic story book without teacher intervention, and observed whether pupils' recall was affected by a number of factors.

Maynard and McKnight (2001) carried out a study of user interaction with electronic books, which investigated the effect of the electronic medium on both comprehension and reading speed. The authors compared children reading an electronic book with children reading the same text in two different printed versions. Thirty participants aged 9-11 years were involved in the study.

The studies described above involve participants interacting with electronic story books. However, there appears to be a lack of original literature on the subject of how children relate to and learn from electronic textbooks. The present study therefore aims to address this issue and is intended to be an investigation of the amount that children can learn from an e-textbook as compared to what they learn from a printed textbook.

\section{Method}

The study involved comparing children's reading and learning from an electronic text with their reading and learning from a similar printed book. The use of the two textbooks was investigated both in terms of children learning in groups, and on an individual basis. 


\section{Sample}

It was decided that the study should concentrate on participants aged 11-12 years. In terms of school attendance in England, this age group is described as Year 7, and part of Key Stage 3 of the National Curriculum. This specific age group was thought to be particularly suitable because they were expected to be accustomed to using computers and so less likely to be subject to any novelty effect. Children of this age routinely use textbooks in UK schools, and as a result, there was a good choice of both printed and computer-aided teaching material suited to both the age range and the research. Furthermore, previous research (discussed above) has involved slightly younger children and it was thought beneficial to involve older children in the current investigation. However, the children were not many years older, so it was assumed that they would remain willing to experiment with different methods of learning

The study consisted of a total of 60 pupils, split into five groups of 12 participants (six boys and six girls in each). Each of the five groups were in turn split into two sub-groups of six (three boys, three girls): one sub-group used the printed textbook, while the other sub-group used the CD-ROM on a single laptop computer provided by the experimenter. The same laptop computer was used for each group using the CDROM. The participants were from four local schools: two studies were carried out at one large school, with participants taken from two different classes. In each case, the class teacher defined the groups, ensuring that they were of mixed ability, according to their general capability, reading skills and computer aptitude.

\section{Experimental design}

Despite thorough research, it proved difficult to find an e-textbook which had an identical printed version. It is recognised that this may represent a limitation in the research, nevertheless, it is thought that the study offers a valuable contribution to research in the area. In order to minimise the effect of this limitation, and to make an appropriate comparison between the printed and electronic resources, two similar books were located. These contain comparative information and are targeted at the same age group. The printed textbook chosen for use in the study was entitled The Medieval World (Stimpson, 1998), specifically written for Key Stage 3 History. The book is highly illustrated and suitable for a mixed ability classroom. The text is broken up into small sections, each illustrated in colour with a relevant diagram or picture. The book has a continuous timeline across the top of each page summarising the main points raised, and providing background information. 
The CD-ROM chosen for the study was Knights, Crusaders \& Castles (Windsor and Windsor, 2001), which supports the National Curriculum Key Stage 3 unit. It is an interactive CD-ROM containing text, animation, graphics and sound. There are hypertext links and a glossary for frequently used and more difficult terms. The CDROM has background music, as well as a range of activities, assignments, quizzes and web links. The software also provides photographs, diagrams and maps designed to support Key Stage 3 learning. A pilot study was carried out, which corroborated the suitability of the proposed experimental procedure, including the time allocated. Some minor alterations were made as a result of the pilot study.

The participants were first asked to fill in a short questionnaire requesting personal details (e.g. name, school, age) and information about their computer experience (see Appendix A). They were then allocated to specific groups and seated around a large desk with either the printed textbook or the e-textbook. They were given 15 minutes to browse, navigate and familiarise themselves with their medium. At this time, if the pupils were having difficulty, they could ask questions and/or for help. Within their groups of six, the participants were tested, via a series of questions, on their ability to understand and locate information in the two resources. The questions were the same for all participants and were set by the experimenter. They were largely based on the activities and quizzes included on the CD-ROM - this ensured that the questions were suitable for the children taking part. As the printed textbook and the CD-ROM were not exactly the same in content, it was essential to ensure that the answers to the questions could be found in both media. It was decided that it would be more equable to include a note at the beginning of the textbook specifying the pages most relevant to the questions they would be asked. This is due to the two resources not matching each other exactly in content: the whole of the CD-ROM content was related to the questions, whereas the printed textbook covered other, less relevant subjects in addition. The questions are shown as Appendix B. The group test questions were the same whether participants were using the printed textbook or the CD-ROM. The time limit was 30 minutes. The children's interactions - both with the textbook and with each other - were observed and noted.

Following the group reading, participants were tested individually on their personal comprehension of the information within the book, this time through a series of multiple choice questions. The participants were re-seated so as not to be directly next to one another, and the laptop and textbook were taken away. Participants were then required to answer the multiple choice test individually - the time limit was 20 minutes. This test was completed in silence. It is difficult to test comprehension 
accurately, since the results obtained from asking questions about the content of a passage are likely to be affected both by the effectiveness of a participant's memory, and by their ability to guess the answers. However, multiple choice questions are widely employed as a comparatively effective means of testing reading comprehension (Greenlee-Moore and Smith, 1996). The method was utilised effectively in the recent study investigating the effect of electronic books on children's comprehension of a story (Maynard and McKnight, 2001), and it was deemed relevant for use in the present study. The questions were set by the experimenter and designed to test whether individuals had understood and learnt from their reading of the two textbooks. The multiple choice questions were therefore mainly based on the group questions. Once again, it was necessary to ensure that the answers to the questions could be found in both media. The multiple choice questions are shown here in Appendix C.

All of the studies were carried out in the respective school library, as this was a quiet area in which to work.

\section{Results and Discussion}

\section{Computer Experience}

All 60 of the participants had access to a computer at school, while fifty of the participants (83\%) had access to a computer at home. Of the 30 pupils using the CDROM as their resource, $23(77 \%)$ had access to a computer at home. All of the participants who indicated having access to a computer at home used it at least once a week. Further details can be found in Table I, which emphasises that the participants use their home computers frequently, indicating that they are computer literate and would respond to, and be able to work with, an e-textbook.

\section{TAKE IN TABLE I}

Although only four pupils used their home computer to read electronic books, 18 (30\%) claimed at some time to have seen or read an electronic book on a computer. In the category of fiction, four children noted having read an electronic version of Harry Potter, and another had read a Star Wars electronic book. With regard to reference works, seven participants had used Encarta, two had made use of World Vista Atlas and one had seen Time Almanac. Titles that came as a free supplement with a newspaper were: The Jungle Book and Let's Explore CD-ROM (one participant having read each). 


\section{The Group Test}

Table II shows that, for all five studies, the group who used the e-textbook as their resource scored an overall higher mark compared to the group who used the printed textbook. The mean score and standard deviation (SD) for the number of correct answers gained by the participants experiencing each version of the text are shown in Table II. A one way analysis of variance (ANOVA) test revealed a significant difference between the two types of text $(F=5.4, p<0.05)$.

\section{TAKE IN TABLE II}

\section{The Individual Multiple Choice Test}

The results indicate that those participants who had used the CD-ROM in the group test gained higher marks in the individual multiple choice test compared to those who used the printed textbook. Those who used the CD-ROM scored a mean of 15.6 marks (62\%), compared to a mean of 14.0 (56\%) for those using the printed textbook. These statistics are summarised in Table III, which also includes the range of results in each case.

\section{TAKE IN TABLE III}

A two-tailed t-test revealed that there was no significant difference between the multiple choice test scores of those who used the CD-ROM and those who used the printed book. However, there was a trend for those using the CD-ROM to score higher on the multiple choice test $(\mathrm{p}=0.1)$.

\section{Gender}

Table IV displays the mean score, standard deviation and range of correct answers obtained by the male and female participants. This Table indicates that the female participants achieved higher marks overall compared to the males. A two-tailed t-test revealed that there was a significant difference between the scores achieved by the different genders $(\mathrm{t}=-3.3, \mathrm{p}<0.002)$.

\section{TAKE IN TABLE IV}

Table V displays the mean score, standard deviation and range for the number of correct answers obtained by the male and female participants, including details of which resource they had used initially. The Table shows that the girls achieved higher results compared to the boys, whichever resource they used. This finding supports the 
National Curriculum results and exams, where girls achieve a higher number of pass marks compared to boys at secondary school (National Literacy Trust, 2000).

An ANOVA test was used to calculate whether there was a significant difference between the multiple choice scores achieved by the boys and girls using each medium. A univariate test revealed that there was no interaction between gender and book type which means that the difference between genders is independent of the type of book used $(\mathrm{F}=0.9, \mathrm{p}=0.8)$.

\section{TAKE IN TABLE V}

\section{Observations}

The data gathered from observations are essentially qualitative in nature - time constraints did not permit any recordings to be made of the children engaged in the study. The observations were conducted carefully and are important in the reporting of the results: they showed that the children using the CD-ROM took longer to find the answers to the group questions, and three of the five groups tested did not finish answering all the questions in the time allowed. This was mainly due to the fact that the CD-ROM had no search facility, and pupils had to navigate around it to find the section they required. The CD-ROM did, in fact, have a main contents screen, but it was not as effective as the contents and index page included in the printed book, which made it easier to find a specific topic. All of the children using the CD-ROM agreed that a search facility would have made finding information on the CD-ROM much easier and more time efficient. This observation highlighted and supported the idea that people are comfortable and familiar with the structure and use of printed textbooks (Catenazzi and Sommaruga, 1994).

The experimenter observed that group work was more productive and structured for those children using the CD-ROM: in all cases, the children were quieter and more eager to get on with their work than those using the printed textbook. Without prompting, the children took turns and rotated around the desk so that each one of them had a chance to use the laptop computer for themselves. The work progress was also more productive in terms of finding the correct answers, as shown by the results collected from both the group tests and the individual multiple choice tests. It should be remembered, however, that their level of interest could have been due, at least in part, to the e-textbook exerting a novelty effect over the participants. 
Each of the five groups was asked what they thought of using a CD-ROM for learning purposes. All agreed that they thought it made learning History easier and more fun. It could be argued that the pupils were simply trying to give answers they thought would be wanted for the research. However, observations of the group using the CDROM indicated that the entire group were very involved with their resource, which may support their claim that they enjoyed using it.

Four of the five groups using the CD-ROM asked for help at some stage during their group test. This consisted of asking how to return to the program when they had accidentally shut it down, or checking the location of a specific topic within the CDROM. Help was given for mechanical issues, such as re-opening the CD-ROM, but help with the questions was not given.

Those using the printed textbook for their resource were a lot more noisy and less well behaved. The pupils lost interest in the task relatively quickly, and it was hard to get the whole group to participate. Although all of the groups using the printed textbook completed the task more quickly than those using the CD-ROM, they did not answer in as much detail or get as many answers right. Therefore, although the printed textbook seems to be a time efficient resource, with all the groups completing the test in the allocated time, it is clear that the pupils did not always find the correct information to the questions within the text, or give sufficiently detailed answers.

None of the groups reading the printed textbook asked for help using it. They all appeared to be competent with using the contents page and the index page to locate specific topics related to the questions they were set. This supports the theory that printed books are generally familiar and straightforward to use, being surrounded by well-established conventions (Catenazzi and Sommaruga, 1994). This observation clearly emphasises one of the advantages that printed textbooks can have over etextbooks.

\section{Conclusions}

The results from the study indicate that using e-textbooks for educational purposes can affect the learning and understanding of pupils. In the group tests, those who used the e-textbook scored significantly higher marks than those who used the printed equivalent. Furthermore, the fact that the participants who used the e-textbook scored higher in the multiple choice test indicates that during the group test they attained a better understanding and remembered facts and information about the subject. 
The participants all agreed that they thought using the CD-ROM was a fun way to learn. Those who had to use the printed textbook for their group text were disappointed that they could not use the CD-ROM instead. It could be concluded, therefore, that children are keen and willing to use textbooks on a computer, and as a result increase their learning capacity.

The research highlighted some advantages associated with using e-textbooks in schools. The first is increased interactivity, and Hambrecht's (2000) theory that eeducation is effective as a result of offering "collaboration and interaction” has been proved correct by the findings from this research: those participants using the CDROM were found to be keen to learn and use their resource. All the children found the music and games on the CD-ROM fun, and observations showed this increased their desire to learn from the it. The interactivity of e-textbooks, therefore gets pupils excited about learning, increases motivation to learn and encourages intellectual curiosity (Buehrle, 2002 and Aedo and Diaz, 2001). The research also indicated that there was increased interactivity with the other pupils involved in the group test - the children who used the CD-ROM for their group test worked more effectively as a group than those who used the printed textbook. This may have been due to the novelty value of the e-textbook, however. Observation during the research noted a certain enjoyment in finding the answers and completing the group test with the CDROM. However, those using the printed book were observably less enthusiastic, with not all of the participants joining in. It could be concluded that e-textbooks are both entertaining and educational and using them makes learning more fun.

It is suggested that the significant difference between the groups using the different textbooks, and the trend for those using the CD-ROM to score higher on the multiple choice test were due to the e-textbook groups achieving a higher level of interactivity with the CD-ROM, better co-operation with the other participants within the group and high levels of enjoyment than the printed book groups. All these factors support the notion that e-textbooks inspire learning in a fun yet educational way. The results from the multiple choice test clearly confirm that those participants who used the CDROM initially for the group test remembered and learnt more about the subject of knights and castles, as they scored higher marks in the individual multiple choice test. The study therefore showed that e-textbooks can support pupils with their learning.

The consequence of introducing e-textbooks into schools would mean a wider range of learning tools. Although the schools that participated in the research had a specific computer room, a library with computers and some classrooms with computer 
equipment, the introduction of e-textbooks into the education sector would necessitate an increase in the number of computers in schools, and a change in teacher roles.

Although e-textbooks can aid and assist in teaching and learning, there remain various factors that can hinder their acceptance, including the difficulty of schools affording computer equipment, and the current limited availability of titles from publishers. It should therefore be noted that, although the study indicated that e-textbooks can help learning and understanding in the classroom, the reality of making them available may prove problematic.

The children who participated in the study were computer literate, however, the majority had problems navigating around the CD-ROM, most particularly when restarting it after an accidental closure. This is perhaps where the printed textbook had an advantage, because those using it already knew how to use both the contents and index page. The CD-ROM group took longer to complete their group test than the printed textbook group, as they found it more time consuming having to navigate around the CD-ROM to find relevant information. A search facility would have reduced the time spent looking for specific information. It could be argued that, had a search facility been available, the scores on the group tests for those using the etextbook might have been even higher, as there would have been more time to answer all of the questions.

The significant difference between the genders showed that the girls achieved higher marks compared to boys regardless of the book resource they used. This supports the published results from the Key Stage 3 results (Department for Education and Skills, 2001), where girls achieved higher results than boys. Although it has been suggested that boys perform better and have greater expectations of success from computer tasks (Littleton, 1999), this study found a significant difference for the CD-ROM which contradicts this theory, and concludes that the girls performed better than the boys in the tests. A report by Duff (2002) comments that girls are becoming more adept with computers, noting that although fewer girls than boys took IT at GCSE level in 2002, but those who did take it achieved better results overall than the boys. Although it should be borne in mind that the ability to answer the multiple choice questions might relate to some extent to their strength of memory, it could be concluded that girls are reaching the same computer literacy levels as boys and are even doing better than them in computer tests (Duff, 2002).

An acknowledged limitation of the study is that, as discussed above, the books used for the study were not identical in content. They were equivalent according to subject 
and recommended age range, but did not contain specifically the same information. It is likely that this limitation had some impact on the results of the study, and further studies would benefit from making use of an electronic version which is identical, or at least more similar, to a printed textbook. The research could also be broadened out to involve a larger number of participants. In addition, it would be worthwhile to investigate the effects of long-term use once the novelty value of the electronic book has subsided. Additional research could include investigating factors such as: different age groups within secondary schools, textbooks covering different subjects, an e-textbook available via the Internet, and observing and comparing the teaching of a class with an e-textbook and a printed textbook.

Finally, it can be concluded that the e-textbook can change and influence creativity and motivate learning, and electronic text has been shown to have a great deal of potential for the academic sector. It is important to acknowledge that the electronic era is changing the form of the textbook, not the content, so the introduction of etextbooks into schools would complement the printed textbook, not replace it. In addition, the increasing number of computers at home, coupled with increasing computer literacy levels and compulsory IT lessons are hastening the arrival of the etextbook. It is highly possible that the secondary school pupils of today will adapt easily to this multimedia society and become the generation of the electronic era (Turnbull, 2000b).

\section{References}

Aedo, I. and Diaz, P. (2001) "Evaluation criteria for hypermedia in educational system”, in Ortega, M. and Bravo, J. (Eds.), Computers and Education: Towards an Interconnected Society, PUBLISHER, PLACE pp. 45-60.

Boyle, Tom (2002) “Towards a Theoretical Base for Educational Multimedia Design”, Journal of Interactive Media in Education (JIME), available from http://www-jime.open.ac.uk/2002/2 [12.02.03]

Buehrle, Sarah (2002) "Students put Books on Computer”. The Enquirer Online. http://enquirer.com/editions/2002/01/16/loc_students_put_books.html [12.12.03]

Catenazzi, Nadia and Sommaruga, Lorenzo (1994) "Hyper-book: A Formal Model for Electronic Books”, Journal of Documentation, Vol. 50, No. 4, pp. 316-332.

Christie, Jack (1998) "Paving the Way for Electronic Textbooks", available from http://www.futureprint.kent.edu/articles/christie01.htm [12.12.03]

Collins Concise Dictionary (1999) (4 ${ }^{\text {th }}$ ed.). Harper Collins, Glasgow. 
Collins, Janet; Hammond, Michael and Wellington, Jerry (1997) Teaching and Learning with Multimedia, Routledge, London.

Cox, A. and Ormes, S. (2001) “E-Books”, Library \& Information Briefings, 96, London: South Bank University.

Desrosiers, R. (1996) “Electronic Books as Teaching Supplements” from the Frontiers in Education Conference, IEEE, 3, 1419-1421.

Duff, R. (2002) “Girls vs Boys - the Changing Pattern of Exam Success”. Childwise (online) http://www.childwise.co.uk/examsuccess.htm [12.12.03].

Dugan (2003) "Beware of Turtleback Syndrome: Overloaded backpacks may be dangerous to children's health.” Idaho Mountain Express (online) http://www.mtexpress.com/2003/03-01-15/03-01-15backpack.htm [12.12.03].

Feather, J. and Sturges, P. (Eds) (1997) International Encyclopaedia of Information and Library Science. Routledge, London.

Department for Education and Skills (2001) "Morris remains confident that 2002 Literary and Numeracy Targets can be achieved", http://www.dfes.gov.uk/pns/DisplayPN.cgi?pn_id=2001_0341 [12.12.03].

Greenlee-Moore, M. and Smith, L. (1996) "Interactive computer software: the effects on young children’s reading achievement”, Reading Psychology, No. 17, pp. 4364.

Hamilton, R.; Richards, C. and Sharp, C. (2001) “An Examination of E-Learning and E-Books", available from http://www.dcs.napier.ac.uk/ mm/socbytes/jun2001/Jun2001_9.htm [12.12.03].

Hambrecht, W. (2000) Exploring a New Frontier. Corporate E-Learning.

Henke, H. (2001) Electronic Books and E-Publishing, Springer Verlag, London.

Landoni, M. and Diaz, P. (2003) "E-education: Design and Evaluation for Teaching and Learning”, Journal of Digital Information, Vol. 3, No. 4.

Landoni, M.; Wilson, R. and Gibb, F. (2000) "From the Visual Book to the WEB Book: the importance of Design", The Electronic Library, Vol. 18, No. 6, pp. 407-419.

Littleton, K. (1999) "Pirate Software Versus Cuddly Bears: It's the Characteristics that Help Learning”, Sesame (Open University Newspaper for Students), No. 191, June/July.

Mayfield, K (2000) “Read A Good E-Textbook Lately?” Wired News. http://www.wired.com/news/culture/0,1284,38059,00.html [12.12.03]. 
Maynard, S. and McKnight, C. (2001) “Children's comprehension of electronic books: an empirical study”, The New Review of Children's Literature and Librarianship, Vol. 7, 2001, pp. 29-53.

National Literacy Trust (2000) “Girls maintain lead as GCSE grades go up” from The Telegraph Online http://www.literacytrust.org.uk/database/resultsupdate.html [02.12.03]

O’Keefe, S. (1995) "Electronic Texts: Hypertextbooks open new worlds of interactive learning on the Internet”, Internet World, Vol. 6, No. 10, pp. 56-58.

Shiratuddin, N., Landoni, M., Gibb, F. and Hassan, S. (2003) "E-Book Technology and its Potential Applications in Distant Education”, Journal of Digital Information, Vol. 3, No. 4.

Shiratuddin, N. and Landoni, M. (2001) Multiple Intelligence Based E-Books, in Centre for Information and Computer Science (LTSN-ICS Conference 2001).

Shiratuddin, N. and Landoni, M. (2000) “Flexibility and Facilities in Children’s Electronic Textbooks”, International Conference in Educational Multimedia, Hypermedia and Telecommunications, ED-MEDIA Proceedings, AACE, Montreal, Canada, pp. 1703-1704.

Stimpson, B. (1998) The Medieval World, Nelson Thornes, Cheltenham.

Trushell J., Burrell, C. and Maitland, A. (2001) Year 5 pupils reading an "Interactive Storybook" on CD-ROM: losing the plot?, British Journal of Educational Technology, Vol. 32, No. 4, pp. 389-401.

Turnbull, G. (2000a) “Ebooks for the Masses? Not Just Yet”, Write the Web (online), http://writetheweb.com/Members/gilest/old/82/view [12.12.03].

Turnbull, G. (2000b) "E-books in Education”, Write the Web (online), http://writetheweb.com/Members/gilest/old/60/view [12.12.03].

Wilson, R. (2001) "Electronic Books as Learning Tools: Designing Usability”, Assignation, Vol. 19, No. 1, pp. 14-18.

Wilson, R. (2003) "E-Education in the UK”, Journal of Digital Information, Vol. 3, No. 4.

Windsor, H. and Windsor, G. (2001) Knights, Crusaders \& Castles, Heinemann, London. PC Pentium 166MHz, Windows 98/NT/2000/XP, 32Mb RAM, CDROM. 


\section{General Questions}

School.

Name

Date of Birth

Do you have access to computer equipment at school?

$\square$ Yes $\square$ No

Have you got a home computer?

$\square$ Yes $\square$ No

If $\underline{\text { YES }}$, how many times a week do you use it?

Everyday

4-6 times a week

2-3 times a week

0-2 times a week

Never

If $\underline{\text { YES, }}$, what purpose do you use it for?

Homework

$\square$ Games

Drawing

Writing

Reading electronic books

Other (please specify)

Have you ever seen or read a book on a computer?

$\square$ Yes $\quad \square$ No 


\section{Group Test}

These questions are to be answered in your groups using your given resource for reference

The numbers in brackets at the end of each question represent the maximum amount of marks you can gain for that question. There are a total of 11 questions, with 50 marks available

Resource Used: CD-ROM/ Textbook

School:

\section{Names:}

1.

2.

3.

4.

5.

6.

Time allowed: 30 minutes

Mark: /50 


\section{INTRODUCING CASTLES}

1. Describe what a castle is and where the best place is to build one

2. Give TWO different types of building materials that could be used to build a castle

1.

2

[2]

3. What year were stone castles first built?

[2]

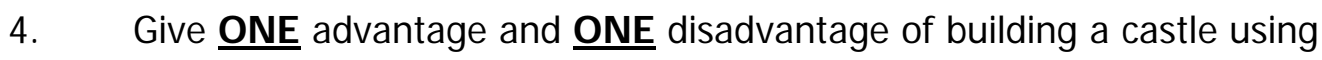
wood.

Advantage.

Disadvantage.

5. (a) What is the Bayeux Tapestry? 
5. (b) What language was it written in?

6. Label the below diagram of a castle using the names given:

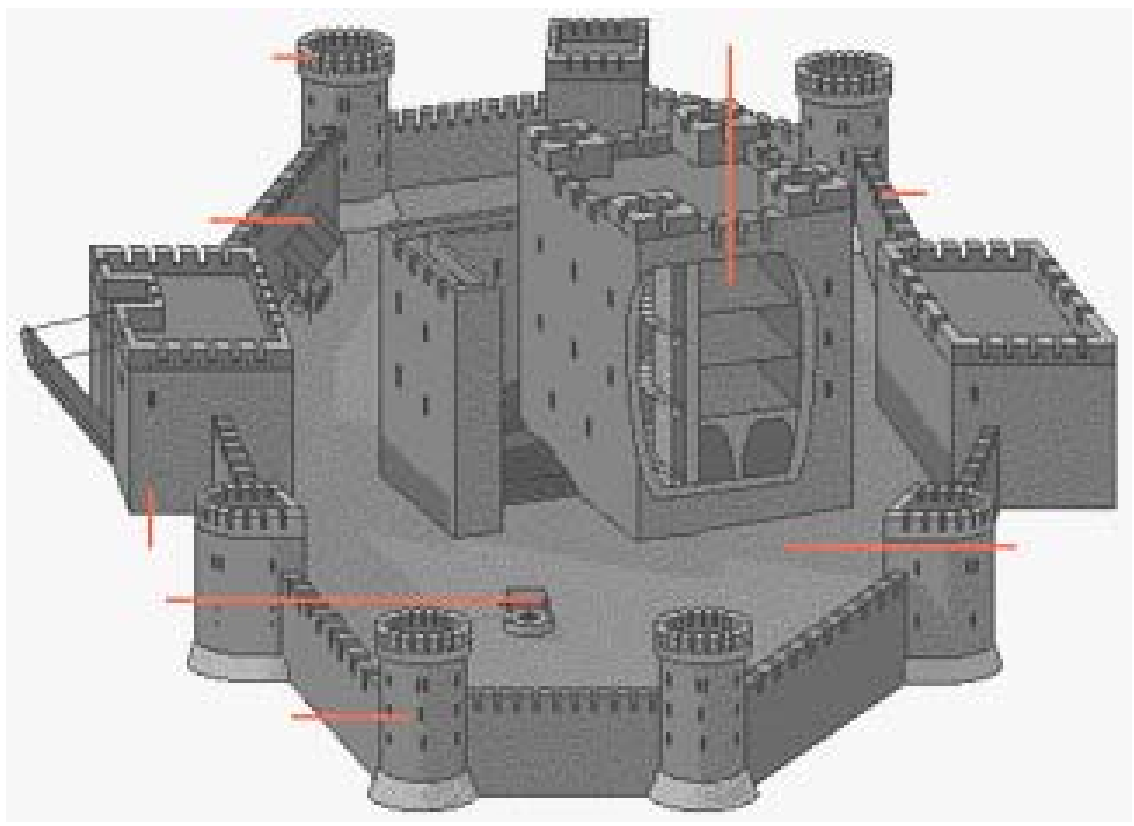

$\begin{array}{ll}\text { Bailey } & \text { Keep } \\ \text { Curtain Wall } & \text { Outside Kitchen } \\ \text { Flanking Tower } & \text { Turret } \\ \text { Gatehouse } & \text { Well }\end{array}$

[8] 
7. (a) Describe what Machicolations were

\section{[2]}

7. (b) Draw what they looked like

8. What were the greatest problems facing the people DEFENDI NG a castle during a siege?

List THREE problems:

1.

2

3

[3]

9. What do you think were the greatest problems facing the people

ATTACKI NG a castle during a siege?

List THREE problems:

1.

2

3

[3]

10. Give examples of FIVE strategies you would use to DEFEND your castle (e.g. weapons, siege artillery) 
1

2.

4

5

[5]

11. Give examples of FIVE strategies you would use to $\underline{\text { ATTACK }}$ a castle (e.g. weapons, siege artillery)

1.

2.

3

4.

5

[5] 


\section{Multiple Choice Test}

\section{These questions are to be answered I NDI VI DUALLY}

Please tick boxes as appropriate.

Only ONE box to be ticked per question.

There are 25 questions in total

Each question is worth 1 mark

Name:

Resource Used: CD-ROM/ Textbook

School:

Time allowed: 20 minutes

Mark: $/ 25$ 


\section{NTRODUCI NG CASTLES}

1. When were most of the Castles in England built?

$1042-1066$

1066-1485

1486-1539

1539-1666

2. Which $\underline{\text { ONE }}$ of the following is the best place to build a castle?

A deserted area

An important town

Overlooking a road or river

Near a monastery

3. In which part of the castle did the Lord and Lady live?

The outer bailey

The chapel

The keep

The palisade

4. Why did the Normans build castles?

To control the area

Because they liked the style of the buildings

They wanted to impress the church authorities

To defeat the Vikings

5. Which of the following provides information about the Norman Conquest?

Magna Carta

Domesday Book

Constitutions of Lanfranc

Bayeux Tapestry 
6. What was a motte?

A ditch around a castle

An enclosure surrounded by a palisade

A wall around a castle

A mound on which a castle was built

7. Which building material was quickest for building a castle?

Stone

Wood

Flint

Brick

8. Which of the following is a good reason for building a castle in stone?

It would cost less

It would be quicker to build

It was easy to defend and difficult to attack

It employed a lot of people

9. What were Machicolations?

War machines

Platforms with holes for firing downwards

Castle towers

Machines for lifting rocks

10. Which of the following best describes a barbican?

An outer gatehouse

A tower in the wall

An arrow with a poisonous tip

A person from a warlike tribe 


\section{FE I N A CASTLE}

11. In the Middle Ages, who lived in a castle?

$\square \quad$ Monks

Kings, Barons and Feudal Nobility

Guides

Pilgrims

12. In Norman times, where did the Lord and Lady, and the Knights eat their meals?

In the solar

In the Great Hall

In the mess

In the kitchen

13. What was the floor covering in the Great Hall?

$\begin{array}{ll}\square & \text { Carpet } \\ \square \quad \text { Tiles } \\ \square \quad \text { Hay } \\ \square \quad \text { Rushes }\end{array}$

14. Which of the following are buildings you might find in the bailey?

Stables

Monastery

Guildhall

Woolhall

15. Why was a reliable water supply essential? 
To water the garden

So people had something to drink if there was a siege

For ornamental fountains

Because people liked to bath everyday

\section{ATTACKI NG AND DEFENDI NG A CASTLE}

16. Stone structures were build on the top of walls to defend people who were firing at attackers below them. These were known as:

Barbican

Machicolations

Bratticing

Drawbridge

17. Which of the following best describes a moat?

A pond in front of the castle

An old type of castle

A stretch of water defending the castle

Water in which fish were kept

18. What is a Siege?

A prolonged attack on a castle

A machine for attacking a castle

A machine for defending a castle

An event in which Knights competed to show their skills

19. The main problem for defenders during a Siege was:

Getting out

Getting in

Clean clothes

Water and food supplies being cut off 
20. Which one of the following is a Siege machine?

$\square \quad$ Trebouchet/Trebuchet

Sword

Scaling ladder

Bratticing

21. Sometimes a structure was built which allowed people to be brought right up to the castle walls on a wheeled ladder. What was this called?

\section{Siege wheels}

Siege mounter

Siege tower

Siege platform

22. Castles that has several rings of curtain walls (the wall surrounding a castle) were known as:

Walled castle

Concentric castle

Circled castle

Enclosed castle

23. A battering ram was a good way of:

Knocking at the door of a castle

Knocking a hole in the wall of a castle

Defending a castle

Digging a tunnel under the castle

24. English archers were famous for using the:

\section{Longbow}

Ballista

Trebuchet

Mangonel 
25. What did crossbows fire?

Metal bolts

Mud

Wooden arrows

Raw animal hides 


\section{TABLES}

\begin{tabular}{lc}
\hline $\begin{array}{l}\text { Frequency of use of } \\
\text { home computer }\end{array}$ & $\begin{array}{c}\text { No of } \\
\text { respondents }\end{array}$ \\
\hline Every day & 13 \\
4-6 times per week & 12 \\
1-3 times per week & 25 \\
Never & 0 \\
\hline
\end{tabular}

TABLE I: Frequency of use of home computer

\begin{tabular}{lcc}
\hline & $\begin{array}{c}\text { Printed textbook } \\
\text { group score } \\
\text { (/50) }\end{array}$ & $\begin{array}{c}\text { CD-ROM } \\
\text { textbook group } \\
\text { score (/50) }\end{array}$ \\
\hline No. of groups & 5 & 5 \\
Mean & 34.6 & 40.2 \\
SD & 4.04 & 3.11 \\
Range & $30-39$ & $30-41$ \\
\hline
\end{tabular}

TABLE II: Group test scores, mean and standard deviation

\begin{tabular}{lcc}
\hline & $\begin{array}{c}\text { Printed textbook } \\
\text { individual test } \\
\text { score (/25) }\end{array}$ & $\begin{array}{c}\text { CD-ROM } \\
\text { textbook } \\
\text { individual test } \\
\text { score (/25) }\end{array}$ \\
\hline No. of participants & 30 & 30 \\
Mean & 14.0 & 15.6 \\
SD & 3.85 & 3.61 \\
Range & $5-20$ & $9-22$ \\
\hline
\end{tabular}

TABLE III: Individual multiple choice test score mean, standard deviation and range

\begin{tabular}{lcc}
\hline & $\begin{array}{c}\text { Male individual } \\
\text { test score (/25) }\end{array}$ & $\begin{array}{c}\text { Female individual } \\
\text { test score (/25) }\end{array}$ \\
\hline Mean & 13.3 & 16.3 \\
SD & 3.64 & 3.36 \\
Range & $5-21$ & $10-22$ \\
\hline
\end{tabular}

TABLE IV: Individual multiple choice test score mean, standard deviation and range (by gender)

\begin{tabular}{llcccc}
\hline & \multicolumn{1}{c}{ Medium } & $\begin{array}{c}\text { N (no of } \\
\text { participants) }\end{array}$ & Mean & SD & Range \\
\hline \multirow{2}{*}{ Boys } & Printed book & 15 & 12.6 & 4.15 & $5-19$ \\
& CD-ROM book & 15 & 13.9 & 3.03 & $9-21$ \\
\multirow{2}{*}{ Girls } & Printed book & 15 & 15.3 & 3.09 & $10-20$ \\
& CD-ROM book & 15 & 17.2 & 3.47 & $11-22$ \\
\hline
\end{tabular}

TABLE V: Individual multiple choice test score mean, standard deviation and range (by gender and resource) 